\title{
Reputation Ontology for Reputation Systems
}

\author{
Elizabeth Chang ${ }^{1}$, Farookh Khadeer Hussain ${ }^{1}$ and Tharam Dillon ${ }^{2}$ \\ ${ }^{1}$ Centre for Extended Enterprise and Business Intelligence and \\ School of Information Systems \\ Curtin University of Technology \\ Western Australia 6845 \\ \{Elizabeth.Chang, Farookh.Hussain\}@, cbs.curtin.edu.au \\ ${ }^{2}$ Faculty of Information Technology, University of Technology, Sydney \\ Broadway, Australia \\ tharam@it.uts.edu.au
}

\begin{abstract}
The growing development of web-based reputation systems in the $21^{\text {st }}$ century will have a powerful social and economic impact on both business entities and individual customers, because it makes transparent quality assessment on products and services to achieve customer assurance in the distributed web-based Reputation Systems. The web-based reputation systems will be the foundation for web intelligence in the future. Trust and Reputation help capture business intelligence through establishing customer trust relationships, learning consumer behavior, capturing market reaction on products and services, disseminating customer feedback, buyers' opinions and end-user recommendations. It also reveals dishonest services, unfair trading, biased assessment, discriminatory actions, fraudulent behaviors, and un-true advertising. The continuing development of these technologies will help in the improvement of professional business behavior, sales, reputation of sellers, providers, products and services. Given the importance of reputation in this paper, we propose ontology for reputation. In the business world we can consider the reputation of a product or the reputation of a service or the reputation of an agent. In this paper we propose ontology for these entities that can help us unravel the components and conceptualize the components of reputation of each of the entities.
\end{abstract}

\section{Introduction}

In this paper we propose two distinct definitions of reputation. The basic definition gives a simplistic view of reputation, and based on this simplistic view of reputation we propose ontology for reputation called the Basic Reputation Ontology. The basic definition and the basic reputation ontology are presented in Section 2.

The sophisticated definition of reputation gives a complete picture of reputation. We call this sophisticated definition of reputation an advanced definition of reputation, and based on this definition we define ontology for reputation termed as Advanced Reputation Ontology. The advanced definition and the advanced reputation ontology are presented in Section 3.

Reputation by itself is a generic term. In a service oriented or a business environment we may in fact refer to the reputation of a trusted agent, or the reputation of a product or service. Due to this we will have a specified and a specialized definition of the 
reputation of a product, service or trusted agent. Based on the specialized definitions of reputation of product, reputation of service and the reputation of a trusted agent, in this paper we will propose reputation ontology for each of these business entities. The ontology for reputation of a trusted agent is presented in Section 4. The ontology for reputation of a service and the ontology for the reputation of a product are presented in Section 5 and Section 6 respectively.

In Section 7 we present ontology for the trustworthiness about an opinion communicated by a recommender. Finally Section 8 concludes the paper.

From existing literature we note that there has been no effort to define ontology for reputation based on the finer granularity of defining reputation (Rahman et al 2003, Aberer et al 2003, Cornelli et al 2003, Xiong et al 2003, Yu et al 2002).

\section{Basic Reputation Ontology}

Reputation is about developing the measure of trustworthiness from Third Party Agent's recommendations, not by the Trusting Agents themselves. This is because the Trusted Agent is unknown to the Trusting Agent.

\subsection{Basic Reputation Ontology}

The Reputation of a Trusted Agent is an aggregated Reputation Value that is recommended by all of the Third Party Recommendation Agents.

The Reputation Value is known as the Reputation of the Trusted Agent. It is an aggregated Trust Value obtained from all of the Recommendation Agents who responded to a Reputation Query.

There are several methods used to aggregate the feedback. Discussing them would be out side the scope of the paper; however, the premise in calculating the basic reputation of a Trusted Agent is outlined below:

\section{Basic Reputation of the Trusted Agent $=\bigcup$ (Recommendation Value)}

where we define $\bigcup$ as an operator for combining the Recommendation Value.

A graphical view of the Basic Reputation Ontology is shown in the following diagram though the use of UML-OCL notation. 


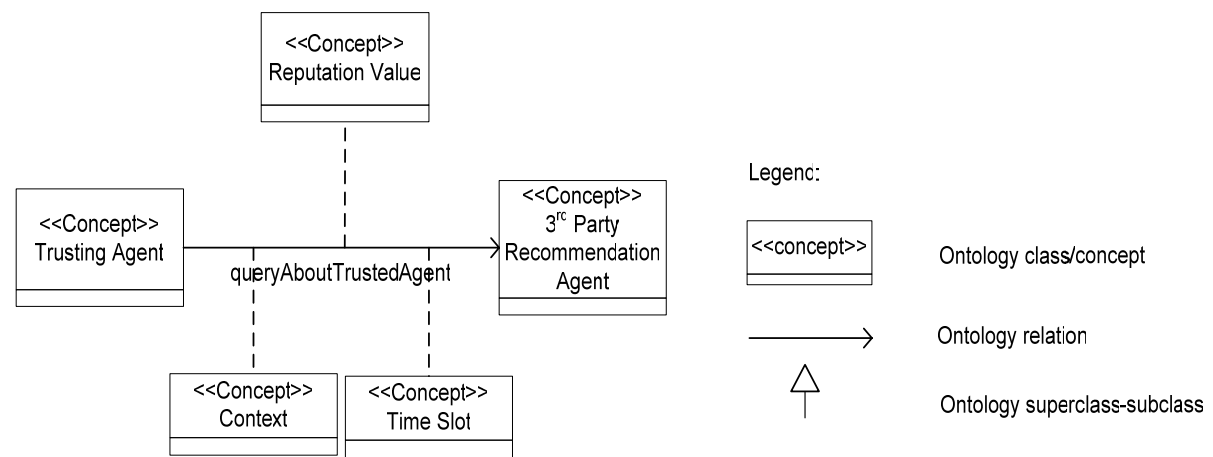

Figure 1. Ontology for Basic Reputation of the Trusted Agent

In the above ontology diagram (Figure 1), boxes represent ontological concept, upArrow represent super class and sub class of concepts. Note that in ontology, there is no need to explicitly define what kind of relationship the super class (upper class) has with sub-class. The most important thing in Ontology is to build a relationship between the concepts, whether it is super-sub class hierarchy relationship or direct association (non-hierarchy). A line with an arrow represents that one concept is closely related to another. A Dotted line represents navigation to association concept. Association classes are used for associations that themselves participate in an association with another class.

Below is a formula table for the Basic Reputation Ontology:

\begin{tabular}{|l|l|}
\hline Formula Name & Formula of Basic Reputation Value \\
\hline Concept & Reputation Value \\
\hline Inferred Attribute & Basic Value \\
\hline Formula & Basic Value $=$ U(Recommendation Value) \\
\hline Description & Basic Reputation Value of the Trusted Agent \\
\hline Variable & Recommendation Value \\
\hline Ad hoc binary relation & QueryAboutTrustedAgent \\
\hline
\end{tabular}

Table 1 Formal Axiom Table of the Basic Reputation Ontology

With the simple (or Basic) Reputation Measure, there could be three problems created:

a) It may end up without a normal distribution in statistical analysis, such as 99\% of Third Party Recommendation Agents giving 'positive' or 'trustworthy' ratings to 99\% of Agents (see e-Bay example in Figure 9.8).

b) It may create doubt on the accuracy and adequacy of the Reputation Measure itself, such as the truthfulness of the Reputation Rating and the depth of the criteria addressed in the reputation.

c) It may lack addressing the dynamic nature of Trust and Reputation, as Trust and Reputation will change over time. A simple 'one value for the lifetime' is not convincing, as many assumptions may not be explored and explained clearly to the end customer and end user. 
Therefore, there is a need to use a more sophisticated measurement method for Reputation. This is introduced in the next section.

\section{Advanced Reputation Ontology}

Advanced reputation measurement methodologies, utilize more sophisticated statistical methods to determine the reputation of a given entity. They have an impact on the accuracy of Reputation measure, thus influencing the quality and moral hazards of service-oriented environments.

\subsection{Advanced Reputation Ontology}

The Reputation of a Trusted Agent is an aggregated Reputation Value that is recommended by all of the Third Party Recommendation Agents. The aggregation is weighted by the Trustworthiness of the Recommendation Agent, the Trustworthiness of the opinion and the ranking of the $1^{\text {st }}, 2^{\text {nd }}$ and $3^{\text {rd }}$ hand opinions.

Mathematically the afore mentioned definition of reputation can be represented as:

Advanced Reputation of the Trusted Agent $=\bigcup$ (Recommendation Value * Trustworthiness of opinion * Perceived $1^{\text {st }} .2^{\text {nd }}$ and $3^{\text {rd }}$ hand opinion $*$ Time elapsed factor)

Where we define $\bigcup$ is an operator for combining and taking into account the Trustworthiness of the Recommendation Agent's opinion, ratio of $1^{\text {st }}$ hand, $2^{\text {nd }}$ hand and $3^{\text {rd }}$ hand opinion, and time factors. This advanced aggregation formula will enable the system to eliminate recommendations that are not trustworthy, selfrecommendations, and those that are malicious.

A graphical view of the Advanced Reputation Ontology is shown in the following diagram through the use of UML-OCL notation.

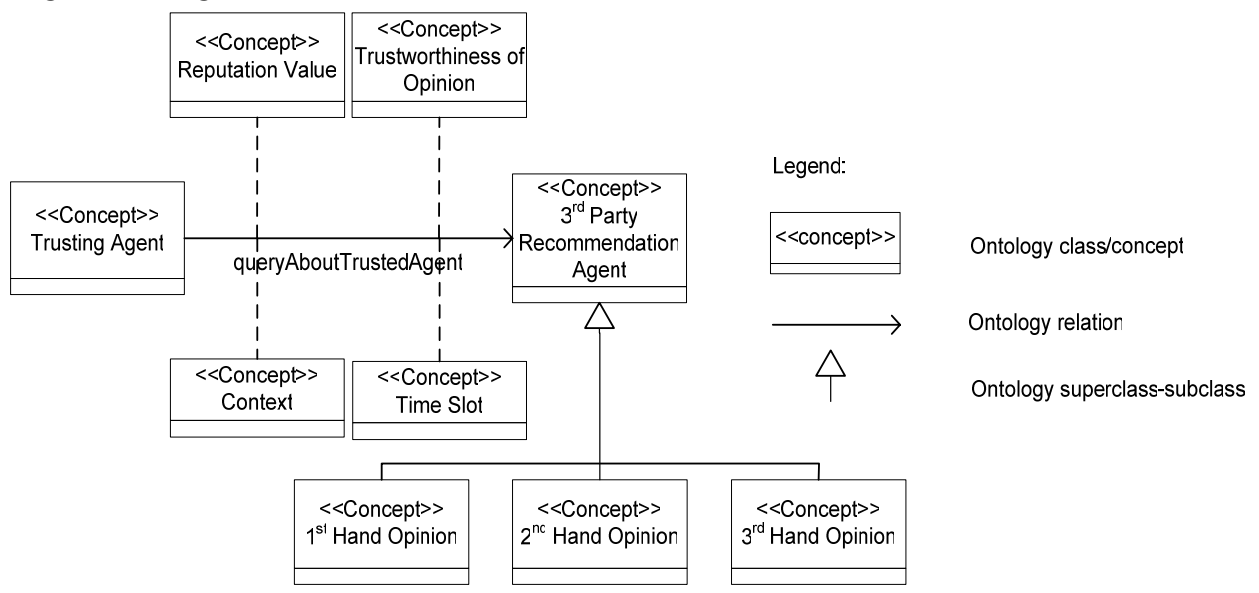

Figure 2. Ontology for Advanced Reputation of the Trusted Agent 
In the above ontology diagram (Figure 2) boxes represent ontological concept, upArrow represent super class and sub class of concepts, and a line with an arrow shows that one concept is closely related to another. Dotted line represents navigation to association concept. Association classes are used for associations that themselves participate in an association with another class.

Below is a formula table for the Advanced Reputation Ontology:

\begin{tabular}{|l|l|}
\hline Formula Name & Formula of Advanced Reputation Value \\
\hline Concepts & $\begin{array}{l}\text { Reputation Value, Trustworthiness of Opinion, Timeslot, 1st Hand Opinion, 2nd } \\
\text { Hand Opinion, 3rd Hand Opinion }\end{array}$ \\
\hline Inferred Attribute & Advanced Value \\
\hline Formula & $\begin{array}{l}\text { Advanced Value = U(Recommendation Value*Trustworthiness Value* }\{\text { 1st Hand } \\
\text { Opinion Value, 2nd Hand Opinion Value, 3rd Hand Opinion Value\}*Time Elapsed } \\
\text { Factor) }\end{array}$ \\
\hline Description & Advanced Reputation Value of the Trusted Agent \\
\hline Variables & $\begin{array}{l}\text { Recommendation Value, Trustworthiness Value, 1st Hand Opinion Value, 2nd Hand } \\
\text { Opinion Value, 3rd Hand Opinion Value, Time Elapses Factor }\end{array}$ \\
\hline $\begin{array}{l}\text { Ad hoc binary } \\
\text { relation }\end{array}$ & QueryAboutTrustedAgent \\
\hline
\end{tabular}

Table 2 Formal Axiom Table of the Advanced Reputation Ontology

\section{Ontology for Reputation of Agent}

\subsection{Ontology for Reputation of Agent}

The Reputation of a Trusted Agent is an aggregated reputation value that is aggregated by the recommendations from all of the Third Party Recommendation Agents. The aggregation is weighted by the Trustworthiness of the Recommendation Agent, the Trustworthiness of the opinion and the ranking of the $1^{\text {st }}, 2^{\text {nd }}$ and $3^{\text {rd }}$ hand opinions that the Trusting Agent obtains through the Reputation Query about the Trusted Agent in a given context and at a given timeslot.

\subsection{Conceptual View of the Ontology for Reputation of Agent}

The graphical view of the Reputation of Agent Ontology is shown in the following diagram below though the use of UML-OCL notation. 


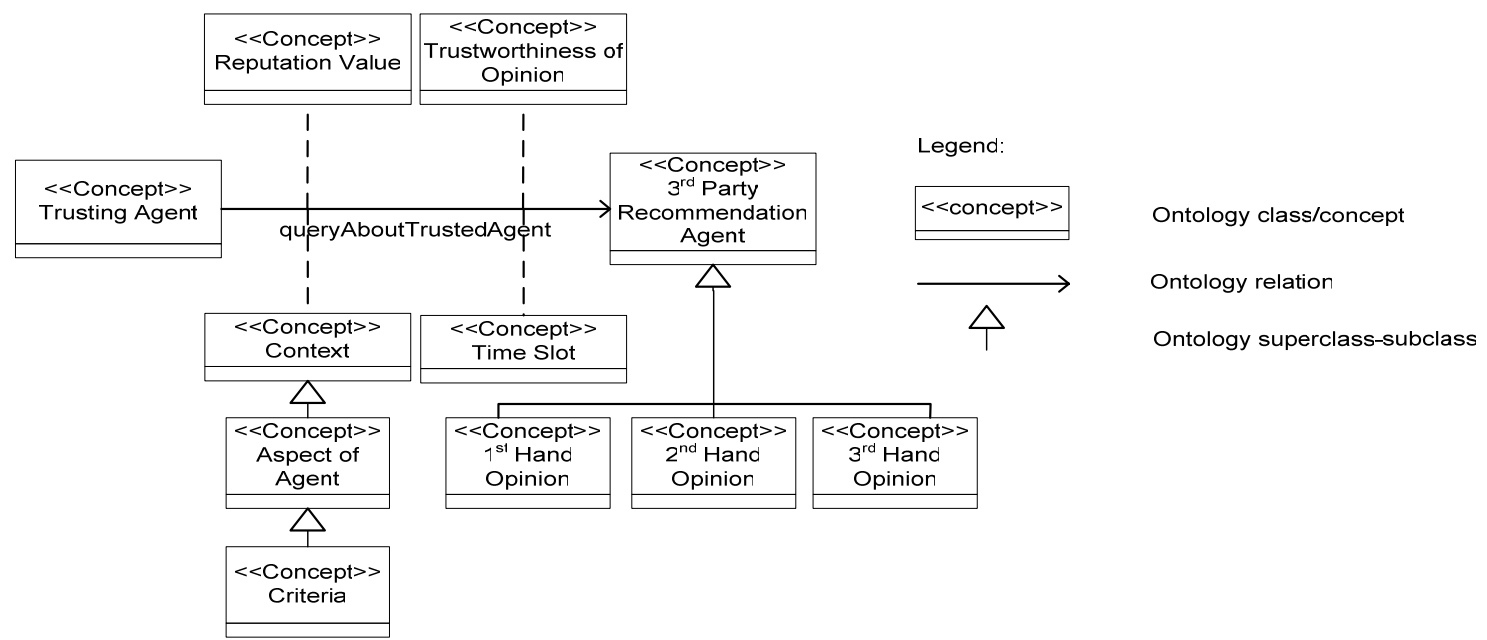

Figure 3 Ontology for Reputation of Agent

In the above ontology diagram (Figure 3), boxes represent ontological concept, uparrow represent super class and sub class of concepts. A line with an arrow represents that one concept is closely related to another. A Dotted line represents navigation to association concept. Association classes are used for associations that themselves participate in an association with another class.

\section{Ontology for Reputation of Service}

The ontology for the Reputation of Services has potential implications for the large growing number of service providers to join e-services. In this section we discuss the use of ontology for the Reputation and the Quality of Service.

\subsection{Ontology for Reputation of Service}

The Reputation of the quality of a Service is an aggregated reputation value that is aggregated by the recommendations from all of the Third Party Recommendation Agents. The aggregation is weighted by the Trustworthiness of the Recommendation Agent, the Trustworthiness of the opinion and the ranking of the $1^{\text {st }}, 2^{\text {nd }}$ and $3^{\text {rd }}$ hand opinions that the Trusting Agent obtains though the Reputation Query about the Trusted Agen, in a given context and at a given timeslot.

\subsection{Conceptual View of the Ontology for Reputation of Service}

The graphical view of the Reputation of Service Ontology is shown in the following diagram though the use of UML-OCL notation. 


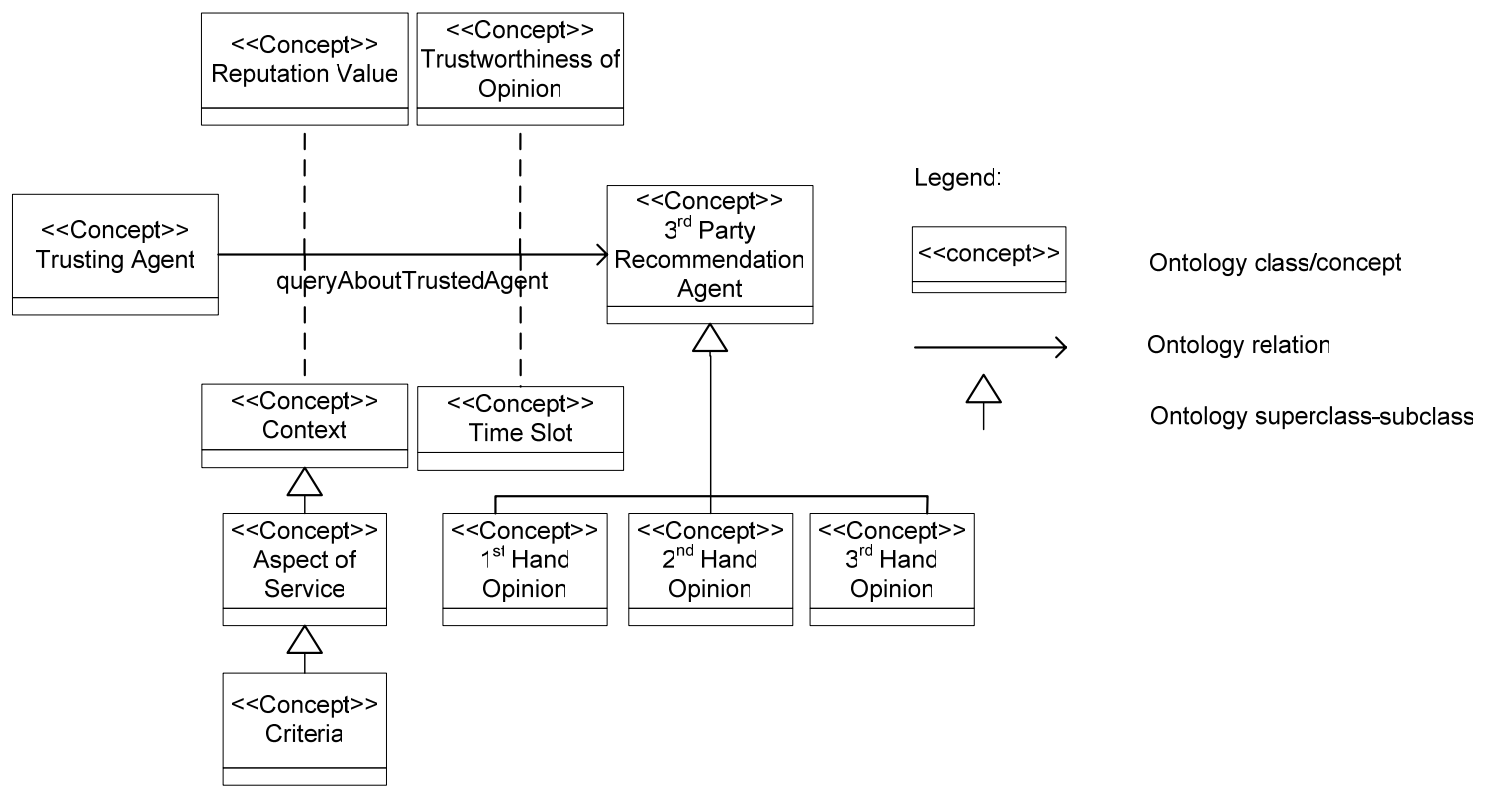

Figure 4 Ontology for Reputation of Service

In the above ontology diagram (Figure 9.13), boxes represent ontological concept, upArrow represent super class and sub class of concepts. A line with an arrow represents that one concept is closely related another. A dotted line represents navigation to association concept. Association classes are used for associations that themselves participate in an association with another class.

\subsection{Ontology for Reputation of Product}

The Reputation of the quality of a Product is an aggregated reputation value that is aggregated by the recommendations from all of the Third Party Recommendation Agents. The aggregation is weighted by the Trustworthiness of the Recommendation Agent, the Trustworthiness of the opinion and the ranking of the $1^{\text {st }}, 2^{\text {nd }}$ and $3^{\text {rd }}$ hand opinions that the Trusting Agent obtains through the Reputation Query about the Trusted Agen, in a given context and timeslot.

\subsection{Conceptual View of the Ontology for Reputation of Product}

The graphical view of the Reputation of Product Ontology is shown in the following diagram though the use of UML-OCL notation. 


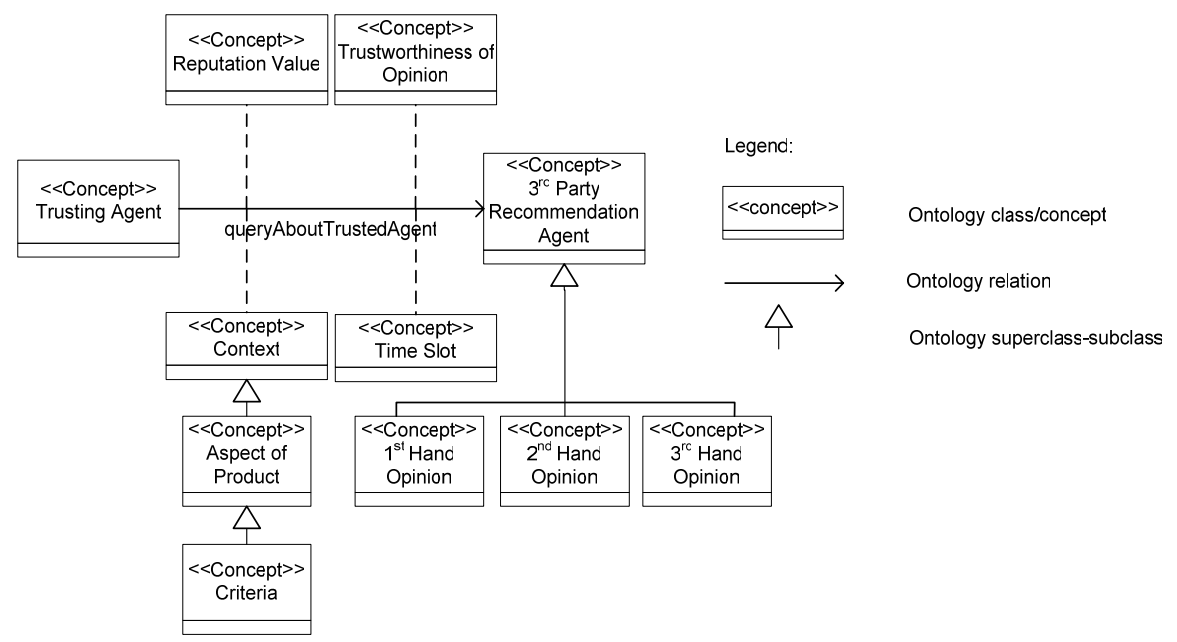

Figure 5 Ontology for Reputation of Product

In the above ontology diagram (Figure 4.9) boxes represent ontological concept, upArrow represent super class and sub class of concepts. A line with an arrow represents that the concept is closely related to another concept. Dotted line represents navigation to association concept. Association classes are used for associations that themselves participate in an association with another class.

\section{Trustworthiness of Opinion Ontology}

\subsection{Opinions in Reputation}

The most crucial factor for reputation measurement (of a trusted agent or a service or a product) is the validation of trustworthiness of the opinion or the recommendation provided by the Third Party Recommendation Agents. The trusting entity after soliciting recommendation from the third party recommendation Agents needs to have an idea of the extent to which it regards each of the recommendations communicated by each of the third party recommendation Agents as being correct. In other words it needs to make known the trustworthiness of the opinion communicated by the third party agent so that the communicated recommendation can be properly weighted. Discussing the mathematical framework for determining the trustworthiness of the opinion is outside the scope of this paper. Further discussion along with detailed examples of how to determine the trustworthiness of the opinion can be found in (Chang, Dillon and Hussain, 2005). In this paper we will provide a ontology for the trustworthiness of the opinion. 


\subsection{Ontology for Trustworthiness of Opinion}

We define the Opinion Trust Ontology as the following Trust Tuple:

Review Trust [Receiver, Reviewer, Review or Feedback, Assessment Criteria, Timeslot, and Trustworthiness of each assessment criterion)

The graphical view of the Trustworthiness of Opinion Ontology is shown in the following diagram though the use of UML-OCL notation

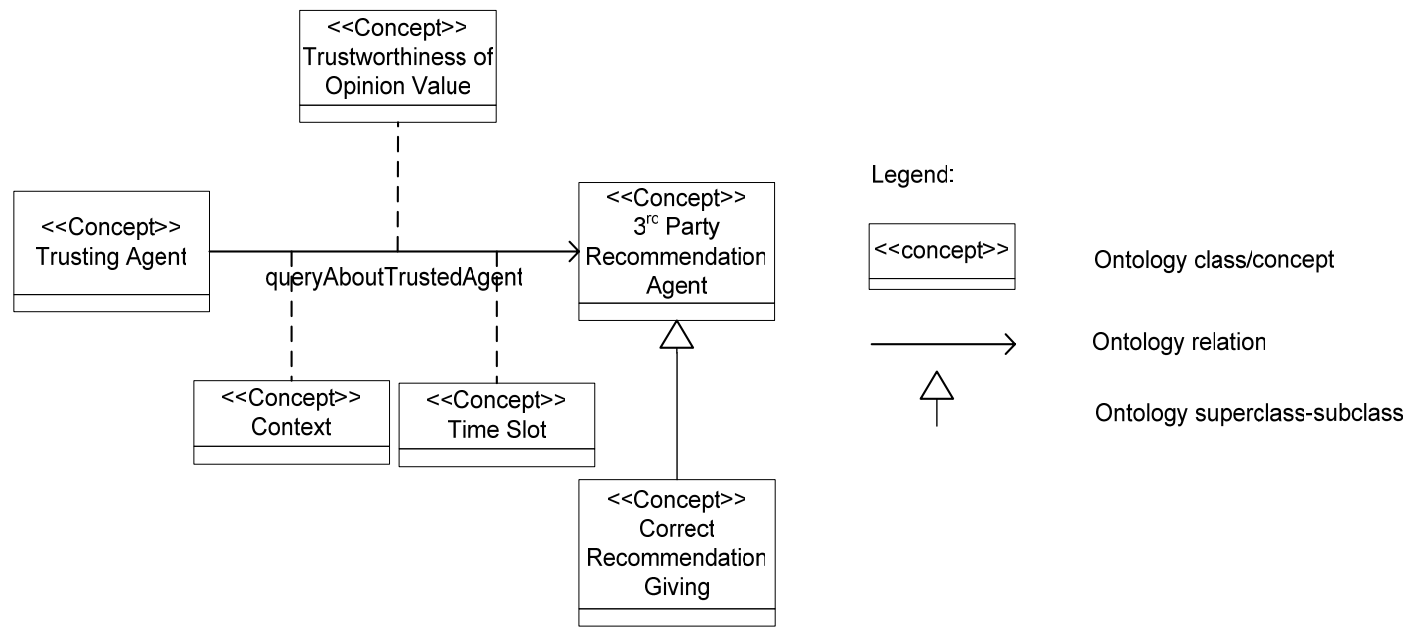

Figure7. Ontology for the Trustworthiness of Opinion

In the above ontology diagram (Figure 7), boxes represent ontological concept, upArrow represent super class and sub class of concepts. A line with arrow represents that the concept is closely related to another concept. Dotted line represents navigation to association concept. Association classes are used for associations that themselves participate in an association with another class.

Below is a table for the Trustworthiness of Opinion Ontology:

\begin{tabular}{|l|l|}
\hline Formula Name & Formula of Trustworthiness of Opinion Value \\
\hline Concepts & Trustworthiness of Opinion Value, Correct Recommendation Giving \\
\hline Inferred Attribute & Trustworthiness Value \\
\hline Formula & $\begin{array}{l}\text { Trustworthiness Value = Actual Trust Value Found On Interaction - } \\
\text { Recommendation Value }\end{array}$ \\
\hline Description & Trust Value of Recommendation Agent in giving correct opinion \\
\hline Variables & Actual Trust Value Found On Interaction, Recommendation Value \\
\hline $\begin{array}{l}\text { Ad hoc binary } \\
\text { relation }\end{array}$ & QueryAboutTrustedAgent \\
\hline
\end{tabular}

Table 4 Formal Axiom Table of the Trustworthiness of Opinion Ontology 


\section{Application of Reputation Ontology and Technology}

Reputation Systems address the quality of goods and services, sellers or service providers, network agents or reviewers, which is based on a number of criteria. Currently, some well known e-commerce portals already start using the reputation systems, such as BizRate, Slashdot, Elance, BBC, Alibris, MoneyControl, Yahoo, Epinions, eBay and CNET. Other popular websites have also adopted reputation systems such as KuroHin.org, Reel.com, Amazon, CDNow.com, GroupLens and MovieLens and CitySearch, to name a few. However, the Reputation technology only adopted at a high level, such as only ranking the products and fewer ranking basic services, and the reputation value is aggregated through simple formulae.

\begin{tabular}{|c|c|c|c|c|c|c|c|c|c|}
\hline & $\begin{array}{c}\text { BizR } \\
\text { ate }\end{array}$ & $\begin{array}{c}\text { eLa } \\
\text { nce }\end{array}$ & $\begin{array}{c}\text { Alibr } \\
\text { is }\end{array}$ & $\begin{array}{c}\text { Mone } \\
\text { y } \\
\text { Cont } \\
\text { rol }\end{array}$ & $\begin{array}{c}\text { Yah } \\
\text { oo }\end{array}$ & $\begin{array}{c}\text { Epini } \\
\text { ons }\end{array}$ & $\begin{array}{c}\text { eB } \\
\text { ay }\end{array}$ & $\begin{array}{c}\text { CN } \\
\text { ET }\end{array}$ & $\begin{array}{c}\text { Mo } \\
\text { vie } \\
\text { Len } \\
\text { s }\end{array}$ \\
\hline $\begin{array}{c}\text { Rating } \\
\text { Merchants } \\
\text { Reputation }\end{array}$ & $\bullet$ & $\bullet$ & $\bullet$ & & $\bullet$ & $\bullet$ & $\bullet$ & $\bullet$ & \\
\hline $\begin{array}{c}\text { Rating } \\
\text { Products } \\
\text { Reputation }\end{array}$ & $\bullet$ & & $\bullet$ & & $\bullet$ & $\bullet$ & & $\bullet$ & $\bullet$ \\
\hline $\begin{array}{c}\text { Rating } \\
\text { Customers } \\
\text { Reputation }\end{array}$ & & $\bullet$ & & & & & & & \\
\hline $\begin{array}{c}\text { Rating Reviews } \\
\text { Reputation }\end{array}$ & & & & $\bullet$ & & & & & \\
\hline $\begin{array}{c}\text { Rating } \\
\text { Reviewers } \\
\text { Reputation }\end{array}$ & & & & & & & & & \\
\hline $\begin{array}{c}\text { Recommendati } \\
\text { on Systems }\end{array}$ & & & & & & & & & $\bullet$ \\
\hline
\end{tabular}

The above table gives a high-level view of the technology adoption (the black-dots) of the listed companies (see horizontal bar) for their business intelligence. Due to the space constraints of this paper, we will not introduce their site; however, readers are encouraged to visit website themselves.

\section{Conclusions}

In this paper we propose a basic and an advanced definition of reputation, and based on this definition we proposed the basic reputation ontology and the advanced reputation ontology respectively. Additionally, we proposed specialized reputation ontology for the reputation of a product, the reputation of a service or the reputation 
of the trusted agent. Finally we proposed ontology for the trustworthiness of the opinion of a recommendation.

\section{References}

Chang, E. , Dillon T, Hussain, F "Trust and Reputation for Service Oriented Environment". John Wiley and Sons, 2005

Abdul-Rahman, A., \& Hailes, S., (2003), Relying On Trust To Find Reliable Information, Available:

http://www.cs.ucl.ac.uk/staff/F.AbdulRahman/docs/dwacos99.pdf (7/08/2003).

Aberer, K. \& Despotovic, Z., (2003), Managing Trust in a Peer-2-Peer Information System, Available: http://citeseer.nj.nec.com/aberer01 managing.html (11/9/2003).

Ba, S., and Pavlou, P., (2002). "Evidence of the Effect of Trust Building Technology in Electronic Markets: Price Premiums and Buyer Behavior". MIS Quarterly, 26 (3).

Bakos, Y., and Dellarocas, C., (2002) "Cooperation without Enforcement?-A comparative Analysis of Litigation and Online Reputation as Quality Assurance Mechanism". Proceedings of the $23^{\text {rd }}$ International Conference on Information Systems (ICIS 2002), Barcelona, Spain.

Cornelli, F., Damiani, E., Vimercati, S., De Capitani di Vimercati, Paraboschi, S. \& Samarati, P., (2003), Choosing Reputable Servents in a P2P Network, Available: http://citeseer.nj.nec.com/cache/papers/cs/26951/http:zSzzSzseclab.crema.unimi.itzSz PaperszSzwww02.pdf/choosing-reputable-servents-in.pdf (20/9/2003).

Dellarocas C., (2003) "The Digitization of Word-of-mouth: Promise and Challenges of Online Feedback Mechanisms" Working Paper, March 2003, Massachusetts Institute of Technology, http://ssrm.com

Xiong, L. \& Liu, L., (2003), A Reputation-Based Trust Model for Peer-to-Peer eCommerce Communities, Available:

http://citeseer.nj.nec.com/xiong03reputationbased.html (9/10/2003).

Yu, B., Singh, M. P., (2002) . 'Distributed Reputation Management for Electronic Commerce.' Computation Intelligence 18 (4) : 535-549. 